\title{
Norois
}

Environnement, aménagement, société

\section{Daviet (S.) - Industrie, culture, territoire}

Paris, L'Harmattan, 2005, 208 p.

\section{Jacques Fache}

\section{CpenEdition}

Journals

Édition électronique

URL : http://journals.openedition.org/norois/1832

DOI : $10.4000 /$ norois. 1832

ISBN : 978-2-7535-1548-2

ISSN : $1760-8546$

\section{Éditeur}

Presses universitaires de Rennes

\section{Édition imprimée}

Date de publication : 1 septembre 2006

Pagination : 97-100

ISBN : 978-2-7535-0342-7

ISSN : 0029-182X

\section{Référence électronique}

Jacques Fache, «Daviet (S.) - Industrie, culture, territoire », Norois [En ligne], 200 | 2006/3, mis en ligne le 12 décembre 2006, consulté le 23 septembre 2020. URL : http://journals.openedition.org/norois/ 1832 ; DOI : https://doi.org/10.4000/norois. 1832 


\section{COMPTE RENDU BIBLIOGRAPHIQUE}

Daviet (Sylvie), Industrie, culture, territoire, Paris, L'Harmattan, 2005, 208 p.

Tiré d'une HDR soutenue en 2003, cet ouvrage propose une approche renouvelée de l'industrie qui réussit à la fois à constituer une rupture par bien de ses idées tout en se situant - et en revendiquant - une continuité vis-à-vis de nombreux pères de la géographie.

Rendre compte d'un tel ouvrage n'est pas une mince affaire, car passé ce constat général, il reste un livre riche, dense, foisonnant, tissant des liens entre de multiples composantes de la géographie que l'histoire de la discipline et les héritages avaient parfois maintenus séparés.

Le ton est donné dès l'introduction. L'industrie sera traitée comme un fait de civilisation, en en privilégiant donc « la dimension culturelle, sociale et philosophique », bouleversant donc à la fois maintes approches classiques et économiques, voire économétriques, mais aussi les discours sur le monde

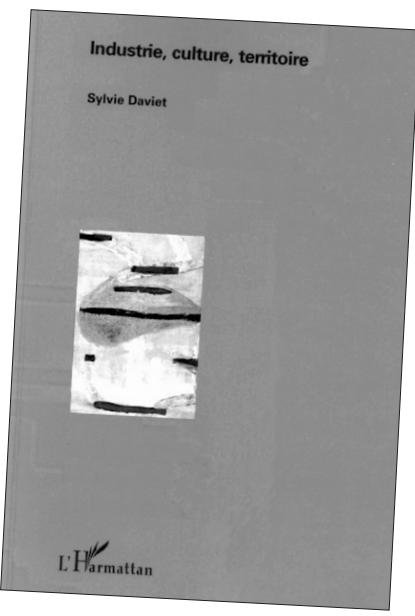
« post-industriel ». L'industrie est donc toujours là, dépassant largement sa seule dimension productive. Dans cette optique, l'intérêt de l'auteur s'est porté progressivement du « quoi? » au " qui ? ", mettant l'ensemble des acteurs au cœur de sa problématique.

Articulé en quatre parties équilibrées, l’ouvrage démarre sur la question de la fin supposée de l'industrie. Nous sommes ainsi emmenés d'emblée d'une vision classique de la crise des industries anciennes à une vision critique, plaçant les acteurs politiques au cœur de la scène. Les sacro-saints coûts, justifiants tous les discours, mais aussi les marchés, sont remis à leur juste place : celle de « choix qui en éliminent d'autres », et non celle de lois "naturelles », donc inexorables et échappant aux sociétés, comme le montre l'exemple des houillères européennes, avec l'Allemagne «qui ne s'est pas précipitée pour appliquer les décisions communautaires ». Mais cette partie va plus loin en développant l'idée de la capacité des industries à secréter une culture, un milieu social et une organisation qui, au final, représentent à la fois un paramètre puissant de territorialisation, mais aussi et surtout une composante identitaire non moins puissante dont la crise fait ressortir la valeur : «Perdre son emploi est sans doute considérable, mais perdre le fondement de son imaginaire et de sa fierté est susceptible d'ébranler plus profondément encore les fondements de la personne. » Ce terme d'imaginaire, qui n'est que très rarement accolé à celui d'industrie, représente l'une des clés que nous retrouverons régulièrement tout au long de l'ouvrage sous diverses formes. Au total, l'image de rupture qui est jointe aux industries traditionnelles en crise est largement survalorisée, alors que le fait industriel est toujours largement présent dans des analyses nouvelles comme celle des districts.

S. Daviet nous donne avec le traitement des districts une relecture de l'industrie intéressante par la place ainsi accordée à la dimension socio-culturelle dans l'organisation du système productif. Ainsi, l'entrepreneur est mis en avant, mais aussi l'innovation, 
les savoir-faire, leur production et leur transmission. Reprenant les thèmes chers à Marshall, les « districtologues » valorisent les dynamiques internes, « endogènes ». Mais S. Daviet en démonte bien les excès qui oublient la dimension politique de certaines créations de districts, l'absence de fonctionnement autarcique et de stabilité. Mais l'essentiel est dans le rôle des représentations qui permet de nuancer la notion de rupture. Le cas de la région marseillaise est significatif de ruptures importantes où le lien entre les époques et cycles qui se «chevauchent » et entre des territoires qui se nourrissent les uns les autres permet d'en nuancer la portée. Les liens entre territorialités rompues et territorialités nouvelles sont donc probables.

Cette première partie appelle naturellement la seconde sur la géographie culturelle. Traitant rarement de l'industrie, elle compte pourtant des auteurs marquants qui se sont tous centrés sur l'interaction culture/industrie/espace. L'affirmation de la culture comme composante de la performance économique change largement la donne actuelle. L'industrie se définit par rapport à un produit, mais aussi des valeurs véhiculées et des histoires, générant une territorialité de l'entreprise se rattachant à l'espace vécu.

$\mathrm{S}$. Daviet nous montre une relation à la technique qui est ancienne et trouve une filiation directe dans les travaux de P. Gourou, identifiant dès les années trente le rôle des « institutions qui assurent et coordonnent les disciplines indispensables à la maitrise de l'eau », faisant de ces systèmes des faits de civilisation. Après une phase de séparation de ces deux composantes, la culture redevient un élément de la territorialisation de l'industrie, avec l'idée de racines, d'expériences collectives à transmettre se doublant de stratégies compétitives individuelles, d'imaginaire, de mythes fondateurs et de leaders charismatiques. Selon elle, ces derniers ont un rôle central dans les fondements des valeurs sur lesquelles repose la société. Toutes ces notions sont présentes dans plusieurs travaux marquants telle la thèse de M. Laferrère. Sa relecture permet ainsi à la fois de redécouvrir les multiples facettes du " complexe industriel lyonnais ", abordé à travers les notions très modernes de «milieu » et de « coordination », mais aussi de (re)découvrir des maîtres (Gilbert, Le Lannou) dans une dimension oubliée donnant la prime à «l'esprit d'entreprise » sur les « données naturelles ». La soie marque l'imaginaire, et «l'esprit de perfection du tissage canut» un «mythe fondateur».

Les anglo-saxons et italiens développent eux aussi des notions culturelles pour rendre compte du fait industriel : embededness (Granovetter), organisation en réseau (Saxenian), relations socio-culturelles dans des « communautés locales » de Becattini, quitte pour ce dernier à idéaliser le local face à la grande entreprise. Cette notion de culture est toutefois à nuancer, puisque selon qu'elle soit « ouverte » ou « fermée », elle permettra toutes les évolutions ou au contraire les pires échecs. Ce paramètre change radicalement la donne pour l'entreprise dont la performance dépend de sa capacité à coordonner des cultures et territoires à divers niveaux d'échelle et dans des mondes divers.

Cette conclusion débouche là encore naturellement sur un troisième temps intitulé « redéfinir l'industrie par le territoire ». Derrière ce titre se masque un champ de réflexion très étendu qui part de la conclusion logique des impacts culturels : «le temps des vieilles théories de la localisation paraît révolu ». L'auteur fait sienne l'idée de P. Veltz du passage d'une géographie des coûts à celle de l'organisation. La performance économique dépend de «la densité et la qualité des coopérations qui se tissent ». La relation entre industrie et territoire se modifie donc.

Ceci étant dit, la situation est complexe entre d'un côté une géographie économique, partant des coûts et des marchés, incarnée par la pensée de P. Claval des années 19601970, et de l'autre une géographie industrielle, relevant de la géographie humaine. Ce débat est largement marqué aujourd'hui par le refus d'une géographie économique dés- 
humanisée, et par le constat de P. Claval lui-même selon lequel l'« homme rationnel » n'éclaire pas tout. De multiples industrialistes réalisent donc d'un autre côté la synthèse culture/industrie (étude du Kolhenpott par Holz, de la notion d'industrie spontanée par Houssel, de la géopolitique de l'industrie par Beckouche et Carroué...), en débouchant sur le problème de la définition et de la place de l'industrie. Sont soulevées les questions de dilution de l'industrie (Montagné-Villette), des quasi-industries (Battiau), de la servicialisation et du glissement vers l'«industry »(Beckouche). L'industrie est toujours motrice, mais elle s'est transformée (Holz et Houssel) et doit être étudiée dans un cadre de mondialisation (Carroué).

Le développement de la nouvelle géographie socio-économique dont les piliers sont G. Benko, A. Lipietz et P. Veltz remet au cœur des préoccupations les grandes entreprises et le rôle des acteurs, en accentuant les aspects de firmes-réseau qui ont besoin de nœuds et relations stables.

La dernière partie aborde la problématique de la territorialisation de l'entreprise qui, dans un contexte de mondialisation et de financiarisation, change de logique et de relation à l'espace.

L'étude des entreprises montre une part croissante de la culture dans sa territorialisation, en commençant par son identité. Le discours ambiant parle souvent d'une mondialisation anonyme, alors que les firmes affirment une identité forte. De ce fait, la territorialisation devient de plus en plus complexe, en particulier du fait de la segmentation de l'entreprise, de l'organisation en réseau, du développement des logiques financières, de la multiplication des associations avec d'autres firmes ou des clients, des programmes européens, etc. Mais dans son fonctionnement même, l'entreprise s'approprie des éléments exogènes par un processus de filtrage culturel dans lequel le chef d'entreprise joue un rôle crucial. L'entreprise organise sa culture, mais son chef impulse un certain état d'esprit. Une étude par S. Daviet des chefs d'entreprises, mais aussi de la généalogie des firmes (méthode nouvelle pour des géographes), donne une vision nuancée du rapport au territoire, faisant dire parfois qu'il y a "surterritorialisation », ou encore culte du territoire bien excessif. En effet, les entreprises de PACA étudiées par l'auteur montrent une spatialité complexe des dirigeants dont les trajectoires sont multiples, et bien souvent en provenance de l'extérieur. Les politiques territoriales comme celle des technopôles sont donc en décalage avec une réalité plus complexe.

Le cheminement intellectuel de S. Daviet nous emmène donc clairement sur des chemins nouveaux d'autant plus intéressants qu'ils offrent une vision synthétique de multiples courants de pensée fragmentés, parfois opposés, et qui partagent pourtant au fond une culture commune qui permet de donner un sens général au tout. Mais cette vision n'est pas stérilisante dans le sens ou elle constituerait une somme définitive et verrouillée. De multiples portes restent ouvertes sur le débat et les recherches en cours, donnant à l'ouvrage un caractère stimulant bien au-delà de son cœur de thématique.

Ainsi se pose en symétrique à la culture la question de la déterritorialisation, évoquée par l'affaire Gemplus (p. 160). Un territoire peut secréter de l'innovation, des entreprises, des leaders charismatiques ; l'État peut lancer des dynamiques qui s'endogénéisent; mais à la fin, le processus définit est réversible, malgré la territorialisation culturelle et l'identité de la firme. Sa « remise en cause » est en soi intéressante. Est-ce vraiment une remise en cause? Ou est-ce l'évolution "naturelle », ou, pour employer un terme plus neutre, logique, d'une start-up dont la réussite l'oblige à passer à un autre stade de développement, tant capitalistique que territorial ? Ce problème rejoint d'ailleurs celui des districts, dont la structure et la culture peuvent être remises en cause par une «success story» mondiale. Y aurait-il donc un cycle de territorialisation, tout comme il y a un cycle du produit ou un cycle des districts? Mais Gemplus pose une autre question qui est celle du « leader charismatique ». L'impact d'une forte per- 
sonnalité est indéniable, mais il entraîne une personnalisation parfois outrancière de la culture interne et externe de l'entreprise. Cet aspect met en exergue la fragilité d'un tel développement, remis en cause avec les changements de génération. Si l'auteur parle par ailleurs de «l'endogénéisation de la filière électronique en PACA », celle de l'endogénéisation de la culture est peut-être moins évidente tant tout repose, pour des entreprises motrices, sur quelques épaules.

Autre piste de réflexion, implicite puisque ce n'était pas son propos : les centralités. Tout au long de son ouvrage, S. Daviet souligne l'importance de l'entreprise pour façonner le territoire, et en particulier de la grande entreprise qui est redécouverte. Or cette dimension nouvelle se retrouve chez Krugman, ou encore Derruder et Wilcox. La territorialisation de l'entreprise restructure la région en faisant voler en éclats les organisations précédentes. Donc jusqu'où va la relation culture/territorialisation? Dans le cœur des métropoles, une continuité et des chevauchements peuvent exister, mais en même temps générer des ruptures profondes dans les espaces situés dans leur orbite et qui de fait mutent quant à leur culture selon une logique exogène. Celle-ci est-elle le fait d'une appropriation locale, ou bien d'un transfert porté par de nouvelles populations migrantes et s'implantant résidentiellement sans raisons, ni logiques, ni continuité, dans ces espaces? Les exemples marseillais alimentent fortement ces pistes.

Ces deux exemples, parmi tant d'autres, alliés aux développements scientifiques de S. Daviet, en font un ouvrage à surtout mettre entre toutes les mains, en particulier pour les jeunes qui envisageraient de devenir chercheurs et qui trouveront là un terreau fertile pour lancer leur propre réflexion. 